\title{
Vaginal Solution Dosage Form
}

National Cancer Institute

\section{Source}

National Cancer Institute. Vaginal Solution Dosage Form. NCI Thesaurus. Code C150014.

Liquid preparation consisting of a solution intended for vaginal use by means of a suitable applicator in order to obtain a local effect. 